\title{
Transcriptional analysis reveals a high impact of conjugated linoleic acid on stearoyl-Coenzyme A desaturase 1 mRNA expression in mice gastrocnemius muscle
}

\author{
Pilar Parra • Francisca Serra • Andreu Palou
}

Received: 7 October 2011/ Accepted: 22 December 2011/Published online: 11 January 2012

(C) Springer-Verlag 2012

\begin{abstract}
We examined the potential implication of skeletal muscle in the fat-lowering effect observed in mice treated with moderate doses of CLA. In experiment 1 , mice fed with a standard-fat diet were orally treated with sunflower oil (control) and 3 or $10 \mathrm{mg}$ CLA mixture/day for 37 days. In experiment 2 , mice were fed with a high-fat diet for 65 days. For the first 30 days, they received the same doses as in experiment 1 and, from that time onwards, animals received double doses. Gene expression of key proteins involved in fatty acid transport, oxidation, regulation of lipid and carbohydrate utilization, composition of muscle fiber, and thermogenesis were determined and, in most of them, no major impact of CLA was seen. Therefore, enhancement of fatty acid oxidation in muscle did not seem to contribute to the antiobesity effect of CLA as seen in other studies with higher CLA doses. However, a strong induction of classically associated lipogenic genes such as Fasn (up to twofold) and, particularly, Scd1 (up to ninefold) was found. This activation could contribute to a protective role in muscle cells, since expression of ER stress markers was decreased and inversely correlated with the induction of Scd1.
\end{abstract}

Keywords Conjugated linoleic acid - Scd1 .

Lipogenesis · Muscle · Obesity

Electronic supplementary material The online version of this article (doi:10.1007/s12263-011-0279-x) contains supplementary material, which is available to authorized users.

P. Parra · F. Serra $(\bowtie) \cdot$ A. Palou

Laboratory of Molecular Biology, Nutrition and Biotechnology,

University of the Balearic Islands and CIBER de Fisiopatología

de la Obesidad y Nutrición (CIBER-OBN), Cra. Valldemossa

Km 7.5, 07122 Palma de Mallorca, Spain

e-mail: francisca.serra@uib.es

\begin{tabular}{|c|c|}
\hline Abbreviation & \\
\hline Acc1 & Acetyl-Coenzyme A carboxylase alpha \\
\hline Acc2 & Acetyl-Coenzyme A carboxylase beta \\
\hline Acox 1 & Acyl-Coenzyme A oxidase \\
\hline Atf3 & Activating transcription factor 3 \\
\hline $\mathrm{Cd} 36$ & CD36 antigen \\
\hline $\mathrm{CHOP}$ & DNA damage-inducible transcript 3 \\
\hline CLA & Conjugated linoleic acid \\
\hline Cpt1b & Muscle carnitine palmitoyltransferase $1 \mathrm{~b}$ \\
\hline Dgat2 & Diacylglycerol O-acyltransferase 2 \\
\hline ER & Endoplasmic reticulum \\
\hline $\mathrm{ERR} \alpha$ & Estrogen-related receptor alpha \\
\hline Exp1 & Experiment 1 \\
\hline Exp2 & Experiment 2 \\
\hline Fabp4 & Fatty acid-binding protein 4 \\
\hline Fasn & Fatty acid synthase \\
\hline GAPDH & $\begin{array}{l}\text { Glyceraldehyde-3-phosphate } \\
\text { dehydrogenase }\end{array}$ \\
\hline Glut4 & Glucose transporter type 4 \\
\hline Insr & Insulin receptor \\
\hline Lpl & Lipoprotein lipase \\
\hline LSD & Least significant difference \\
\hline MCAD & $\begin{array}{l}\text { Medium-chain acyl-Coenzyme A } \\
\text { dehydrogenase }\end{array}$ \\
\hline MyHC-b & Myosin heavy polypeptide 7 beta \\
\hline MyHC-IIa & Myosin heavy polypeptide 2 \\
\hline MyHC-IIb & Myosin heavy polypeptide 4 \\
\hline MyHC-IIx/d & Myosin heavy polypeptide 1 \\
\hline Pdk4 & Pyruvate dehydrogenase kinase, isoenzyme 4 \\
\hline PGC- $1 \alpha$ & $\begin{array}{l}\text { Peroxisome proliferative-activated receptor } \\
\text { gamma coactivator } 1 \text { alpha }\end{array}$ \\
\hline PGC- $1 \beta$ & $\begin{array}{l}\text { Peroxisome proliferative-activated receptor } \\
\text { gamma coactivator } 1 \text { beta }\end{array}$ \\
\hline $\operatorname{PPAR} \alpha$ & $\begin{array}{l}\text { Peroxisome proliferator activator receptor } \\
\text { alpha }\end{array}$ \\
\hline
\end{tabular}

\section{Abbreviations}

Acetyl-Coenzyme A carboxylase beta

Acyl-Coenzyme A oxidase

Activating transcription factor 3

DNA damage-inducible transcript 3

Conjugated linoleic acid

Cpt1b

Muscle carnitine palmitoyltransferase $1 b$

Endoplasmic reticulum

Estrogen-related receptor alpha

Experiment 1

Fatty acid-binding protein 4

Fatty acid synthase

dehydrogenase

Insulin receptor

Lipoprotein lipase

Medium-chain acyl-Coenzyme A

dehydrogenase

Myosin heavy polypeptide 2

MyHC-IIx/d Myosin heavy polypeptide 1

Pdk4

Pyruvate dehydrogenase kinase, isoenzyme 4

Peroxisome proliferative-activated receptor gamma coactivator 1 alpha

gamma coactivator 1 beta

alpha 


\begin{tabular}{|c|c|}
\hline $\operatorname{PPAR} \delta$ & $\begin{array}{l}\text { Peroxisome proliferator activator receptor } \\
\text { delta }\end{array}$ \\
\hline Scd1 & Stearoyl-Coenzyme A desaturase 1 \\
\hline SEM & Standard error of the mean \\
\hline Sptlc1 & $\begin{array}{l}\text { Serine palmitoyltransferase, long-chain } \\
\text { base subunit } 1\end{array}$ \\
\hline Sptlc2 & $\begin{array}{l}\text { Serine palmitoyltransferase, long-chain } \\
\text { base subunit } 2\end{array}$ \\
\hline SREBP-1c & Sterol regulatory element-binding factor 1 \\
\hline Ucp3 & Uncoupling protein 3 \\
\hline Xbp1 & $\mathrm{X}$-box binding protein 1 \\
\hline Xbp1s & $\mathrm{X}$-box binding protein 1 , spliced form \\
\hline
\end{tabular}

\section{Introduction}

Conjugated linoleic acid (CLA) refers to a group of positional and geometric-conjugated isomers of linoleic acid that exhibits a number of biological actions (for a review see Benjamin and Spener 2009). The beneficial effects of CLA on body weight and adiposity have been extensively studied in different animal models and, particularly, the mixtures containing the two most active isomers (trans-10, cis-12- and cis-9, trans-11-CLA). Several mechanisms of action have been proposed, most of them involving adipose tissue functions: decreased lipid synthesis, increased lipolysis, decreased preadipocyte proliferation and differentiation, and increased apoptosis (for a review see Kennedy et al. 2010). Thus, most studies have focused on adipose tissue, which seems to be the main target of CLA action, and less attention has been paid to other organs or tissues, such as muscle, which also play a significant role in energy metabolism.

Skeletal muscle is one of the most metabolically demanding tissues. It may account for $50 \%$ of energy expenditure and $75 \%$ of glucose disposal. Consequently, muscle has a significant influence in nutrient partitioning, insulin sensitivity, and blood lipid profile. Moreover, skeletal muscle presents a notable metabolic flexibility in response to physiological and pathophysiological conditions. Concerning the impact of CLA, there is some evidence of its anabolic properties on lean body mass in animals (DeLany et al. 1999; Park et al. 1997; Peters et al. 2001), which is of interest since body weight loss often results in the loss of lean body mass. However, the specific effects of CLA on skeletal muscle and the mechanism of action are still unclear (Martin et al. 2000; Park et al. 1997; Rahman et al. 2001; Zabala et al. 2006). We have previously reported that moderate doses of an equimolar mix of trans-10, cis-12 and cis-9, trans-11 CLA isomers reduce body fat accumulation and are accompanied by an amelioration of the inflammatory profile in adipose tissue in both mice fed a standard-fat (Parra et al. 2010b) and a high-fat diet (Parra et al. 2010a). In the present work, we focused on the potential contribution of skeletal muscle to the fat-lowering effect of dietary CLA, by modulating the profile of expression of key proteins involved in energy and lipid metabolism in gastrocnemius muscle and in particular of stearoyl-Coenzyme A desaturase 1 (Scd1).

\section{Methods and materials}

Animals and diets

Male C57BL/6J mice from Charles River (Barcelona, Spain) weighing $20 \pm 0.2 \mathrm{~g}$ were housed in groups of four in plastic cages and kept in a 12 -h light/dark cycle at $22^{\circ} \mathrm{C}$. These mice were used in two independent experiments with different dietary regimens. In Experiment 1 (Exp1), animals were fed ad libitum with a standard diet (D12450B, Research Diets Inc, New Brunswick), which contains $10 \%$ calorie content as fat. In Experiment 2 (Exp2), animals were fed ad libitum with a high-fat diet (D12451, Research Diets Inc, New Brunswick), which contains $45 \%$ calorie content as fat. Food intake and body weight were recorded every 3 days throughout the experiments. Fresh food was provided to the mice biweekly.

All experimental procedures were performed according to both national and institutional guidelines for animal care and use.

\section{CLA treatment}

Mice were orally treated with CLA (Tonalin ${ }^{\circledR}$ TG 80 derived from safflower oil, kindly provided by Cognis). Tonalin is composed of triglycerides containing approximately $80 \%$ conjugated linoleic acid with a 50:50 ratio of the active CLA isomers cis-9, trans-11 and trans-10, cis-12. Control animals received an adequate amount of commercial sunflower oil to achieve isocaloric load between groups.

In Exp1, mice were randomly assigned to three experimental groups ( $n=12$ each group) for 37 days: control (sunflower oil), CLA1 (3 mg CLA/day), or CLA2 (10 mg CLA/day).

In Exp2, mice were also assigned to three oral treatments ( $n=8$ each group) for 65 days: control (sunflower oil), CLA3, or CLA4. For the first 30 days, animals received the same doses of CLA used in Exp1, from that time onwards, animals received double dose. Therefore, animals received a daily amount of $6 \mathrm{mg}$ CLA in CLA3 and of $20 \mathrm{mg}$ in CLA4 group for the last 35 days of treatment. 
Killing and tissue sampling

Mice from Exp1 were killed under feeding conditions and from Exp2 were fasted for $10 \mathrm{~h}$ before killing. At the beginning of the light cycle, animals were anaesthetized by intraperitoneal injection of a mixture of xylazine $(10 \mathrm{mg} /$ $\mathrm{kg}$ body weight) and ketamine (100 mg/kg body weight). Gastrocnemius muscle was rapidly removed, weighed, rinsed with saline containing $0.1 \%$ diethyl pyrocarbonate (Sigma, Madrid, Spain), frozen with nitrogen liquid, and stored at $-70^{\circ} \mathrm{C}$.

\section{Myoblast culture and treatment}

The murine skeletal muscle cell line $\mathrm{C} 2 \mathrm{C} 12$ was cultured in the growth medium DMEM (Sigma, Madrid, Spain) supplemented with $10 \%$ fetal bovine serum (Invitrogen, Gibco, Spain), $3 \mathrm{mM}$ L-glutamine (Sigma, Madrid, Spain), penicillin $(50 \mathrm{U} / \mathrm{ml})$, and streptomycin $(50 \mu \mathrm{g} / \mathrm{ml})$ (Sigma, Madrid, Spain). Cells were maintained at $37^{\circ} \mathrm{C}$ in humidified $95 \%$ air and $5 \% \mathrm{CO}_{2}$ atmosphere. To induce differentiation, $\mathrm{C} 2 \mathrm{C} 12$ myoblasts were plated at an initial density of $3 \times 10^{4}$ cells $/ \mathrm{cm}^{2}$ in 12 -well culture dishes for $24 \mathrm{~h}$, allowing them to reach $80 \%$ confluence; then, growth media was replaced with DMEM containing antibiotics, $3 \mathrm{mM}$ L-glutamine, and $2 \%$ horse serum, referred to as differentiation media. Medium was changed every 2 days. After 9 days, differentiated $\mathrm{C} 2 \mathrm{C} 12$ myotubes were incubated with different treatments using serum-free differentiation media.

Trans-10, cis-12 and cis-9, trans-11 CLA isomers (>98\%) were obtained from Matreya (Teknokroma, Barcelona, Spain), and a working mixture $200 \mathrm{mmol} / \mathrm{L}$ of both isomers was prepared. Insulin and palmitic acid were obtained from (Sigma, Madrid, Spain). All fatty acids were dissolved in ethanol and conjugated to BSA with a final molar ratio of CLA/BSA of 5:1 before addition to the medium. Control cells received the proportional volume of ethanol and BSA.

\section{RNA extraction}

Total RNA from gastrocnemius and C2C12 cells was extracted using Tripure Reagent (Roche Diagnostic Gmbh, Mannheim, Germany) according to the manufacturer's instructions. Isolated RNA was quantified using the NanoDrop® Spetrophotometer ND-1000 (NadroDrop Technologies, Wilmington, DE, USA) and its integrity confirmed using agarose gel electrophoresis.

mRNA expression analysis

Real-time PCR was used to measure mRNA expression levels of target genes. $0.5 \mu \mathrm{g}$ of total RNA (in a final volume of $10 \mu \mathrm{L}$ ) was denatured at $90^{\circ} \mathrm{C}$ for $1 \mathrm{~min}$ and then reverse-transcribed to cDNA using MuLV reverse transcriptase (Applied Biosystem, Madrid, Spain) at $42^{\circ} \mathrm{C}$ for $60 \mathrm{~min}$, with a final step of $5 \mathrm{~min}$ at $99^{\circ} \mathrm{C}$ in a Perkin-Elmer 9700 Thermal Cycler (PerkinElmer, Wellesley, MA). Realtime PCR was performed using the Applied Biosystems StepOnePlus $^{\text {TM }}$ Real-Time PCR Systems (Applied Biosystems, Madrid, Spain) with the following profile: $10 \mathrm{~min}$ at $95^{\circ} \mathrm{C}$, followed by a total of 40 temperature cycles $(15 \mathrm{~s}$ at $95^{\circ} \mathrm{C}$ and $1 \mathrm{~min}$ at $60^{\circ} \mathrm{C}$ ). Each PCR was performed in a total volume of $6.25 \mu \mathrm{L}$, made from diluted cDNA template, forward and reverse primers ( $1 \mu \mathrm{M}$ each), and Power SYBER Green PCR Master Mix (Applied Biosystems, CA, USA). Primer sequences are listed in Online Resource 1. All primers were purchased from Sigma (Madrid, Spain). In order to verify the purity of the products, a melting curve was produced after each run according to the manufacturer's instructions. PCR products were also analyzed by electrophoresis in an ethidium bromide-stained agarose gel to check that a single amplicon of the expected size was indeed obtained. The relative quantification of each target gene was calculated based on efficiency and the crossing point deviation of an unknown sample versus a control. Gene expression data derived from gastrocnemius muscle were normalized to the mean of two housekeeping genes: $\beta$-actin and GAPDH, while data derived from C2C12 culture experiments were normalized relative to the levels of 18S. Results from CLA-treated groups were expressed as relative fold induction relative to the control group.

Statistical analysis

Data are presented as mean \pm SEM. One-factor ANOVA was used to determine the significance of the differences between groups. If there was a significant difference, a least significant difference (LSD) test was used to determine the particular effect that caused that difference. $P<0.05$ was considered statistically significant, and different superscripts discriminate differences between groups. Linear relationships between key variables were tested using Pearson's correlation coefficients. The analyses were performed using the SPSS program for Windows version 16 (SPSS, Chicago, IL, USA).

\section{Results}

Transcriptional effect of CLA supplementation on gene indicators of substrate handling and energy metabolism

Analysis of the expression of peroxisome proliferativeactivated receptor gamma coactivator 1 alpha (PGC- $1 \alpha$ ) and transcription factors-estrogen-related receptor alpha 
$(\mathrm{ERR} \alpha)$, peroxisome proliferator activator receptor alpha $(\operatorname{PPAR} \alpha)$, and delta $(\operatorname{PPAR} \delta)$ — which are known regulators of lipid and carbohydrate metabolism in muscle was not affected by CLA supplementation in either of the dietary treatments (Tables 1 and 2). In accordance, the same pattern was seen in mRNA levels of biomarkers of glucose metabolism (glucose transporter type 4 (Glut4), pyruvate dehydrogenase kinase, isoenzyme $4(\operatorname{Pdk} 4)$, and Hexokinase 2), fatty acid transport and oxidation (CD36 antigen (Cd36), lipoprotein lipase ( $\mathrm{Lpl}$ ), muscle carnitine palmitoyltransferase 1b (Cpt1b), acyl-Coenzyme A oxidase (Acox1), medium-chain acyl-Coenzyme A dehydrogenase (MCAD)), or uncoupling protein 3 (Ucp3) expression (Tables 1 and 2). Myosin heavy-chain isoform expression, which is typically used as an indicator of the composition of the fiber types in muscle, was not affected by CLA treatment in either of the dietary treatments, standard-fat feeding or high-fat diet (Tables 1 and 2).

From the whole set of genes studied, the effect of CLA was manifested on the expression of peroxisome proliferative-activated receptor gamma coactivator 1 beta (PGC$1 \beta)$, which increased in groups treated with CLA under standard-fat feeding $(P<0.05)$ (Table 1$)$; on expression of fatty acid-binding protein 4 (Fabp4), which increased in the group treated with the highest dose of CLA under high-fat feeding $(P<0.01)$ (Table 2$)$; and on expression of insulin receptor (Insr), which decreased in CLA animals fed the high-fat diet $(P<0.01)$ (Table 2$)$.

Impact of CLA supplementation on lipogenic gene expression

Unexpectedly, mRNA levels of genes involved in de novo lipogenesis were increased by CLA supplementation. Induction of fatty acid synthase (Fasn) was observed in both dietary conditions, in the groups treated with the highest dose (1.9 times $(P<0.05)$ in standard-fat and 1.6 times $(P<0.05)$ in high-fat diet versus their respective controls (Fig. 1a, b). A remarkable increase in the expression of Scd1 mRNA was seen in all the groups treated with CLA and, particularly, under the high-fat diet. Therefore, in animals fed the standard-fat diet, Scd1 was higher in CLA groups, reaching statistical significance with the highest dose (2.5-fold induction, $P<0.05$ ) in comparison with the control group (Fig. 1a). In Exp2, under the high-fat diet, a dose-dependent strong induction of Scd1 mRNA was observed (3.2-fold induction in CLA3 $(P<0.001)$ and 8.6 -fold $(P<0.001)$ in CLA4 groups with respect to the control group).

More modest effects of CLA, modulated by the dietary treatment, were also evidenced in the expression of other markers of lipogenic activity. Under standard-fat diet (Exp1), the highest dose of CLA produced a slight but statistically significant increase in the transcript of sterol
Table 1 Relative changes in the expression of genes encoding transcription factors and co-activators, myogenic markers, and proteins involved in substrate handling and energy metabolism in gastrocnemius muscle of mice treated with CLA and fed a standard-fat diet

\begin{tabular}{|c|c|c|c|}
\hline \multicolumn{4}{|c|}{ Experiment 1 (standard-fat diet) } \\
\hline & Control & CLA1 & CLA2 \\
\hline \multicolumn{4}{|c|}{ Transcriptional co-activators } \\
\hline PGC- $1 \alpha$ & $1.00 \pm 0.11$ & $0.87 \pm 0.04$ & $1.11 \pm 0.10$ \\
\hline PGC- $1 \beta$ & $1.00 \pm 0.06^{\mathrm{a}}$ & $1.21 \pm 0.05^{\mathrm{b}}$ & $1.24 \pm 0.05^{\mathrm{b}}$ \\
\hline \multicolumn{4}{|c|}{ Contractility/myogenic markers } \\
\hline MyHC-b & $1.00 \pm 0.17$ & $0.98 \pm 0.10$ & $0.91 \pm 0.08$ \\
\hline MyHC-IIa & $1.00 \pm 0.09$ & $0.98 \pm 0.06$ & $1.02 \pm 0.06$ \\
\hline MyHC-IIb & $1.00 \pm 0.05$ & $0.96 \pm 0.03$ & $0.96 \pm 0.04$ \\
\hline MyHC-IIx/d & $1.00 \pm 0.06$ & $1.01 \pm 0.04$ & $1.14 \pm 0.10$ \\
\hline \multicolumn{4}{|c|}{ Transcription factors } \\
\hline $\mathrm{ERR} \alpha$ & $1.00 \pm 0.05$ & $0.95 \pm 0.05$ & $0.90 \pm 0.04$ \\
\hline $\operatorname{PPAR} \alpha$ & $1.00 \pm 0.10$ & $0.88 \pm 0.04$ & $0.90 \pm 0.06$ \\
\hline $\operatorname{PPAR} \delta$ & $1.00 \pm 0.03$ & $0.99 \pm 0.02$ & $1.07 \pm 0.03$ \\
\hline \multicolumn{4}{|c|}{ Fatty acid metabolism } \\
\hline $\mathrm{Cd} 36$ & $1.00 \pm 0.07$ & $0.82 \pm 0.04$ & $0.88 \pm 0.09$ \\
\hline Lpl & $1.00 \pm 0.06$ & $0.97 \pm 0.03$ & $0.98 \pm 0.05$ \\
\hline Cpt1b & $1.00 \pm 0.18$ & $1.22 \pm 0.09$ & $1.14 \pm 0.09$ \\
\hline Acox 1 & $1.00 \pm 0.04$ & $0.95 \pm 0.02$ & $1.05 \pm 0.04$ \\
\hline MCAD & $1.00 \pm 0.11$ & $1.01 \pm 0.09$ & $1.21 \pm 0.07$ \\
\hline Fabp4 & $1.00 \pm 0.08$ & $1.02 \pm 0.07$ & $1.16 \pm 0.07$ \\
\hline \multicolumn{4}{|c|}{ Glucose and insulin metabolism } \\
\hline Glut4 & $1.00 \pm 0.06$ & $1.11 \pm 0.05$ & $1.10 \pm 0.04$ \\
\hline Pdk4 & $1.00 \pm 0.10$ & $0.79 \pm 0.07$ & $0.84 \pm 0.10$ \\
\hline Hexokinase 2 & $1.00 \pm 0.05$ & $0.94 \pm 0.03$ & $1.00 \pm 0.04$ \\
\hline Insr & $1.00 \pm 0.06$ & $0.97 \pm 0.06$ & $0.95 \pm 0.05$ \\
\hline \multicolumn{4}{|c|}{ Energy expenditure } \\
\hline Ucp3 & $1.00 \pm 0.09$ & $0.86 \pm 0.07$ & $1.03 \pm 0.10$ \\
\hline
\end{tabular}

RNA was isolated from gastrocnemius muscle of animals fed a standard diet and receiving an oral dose of CLA $(3 \mathrm{mg} /$ day in CLA1 and $6 \mathrm{mg} /$ day in CLA2) for 37 days. Expression levels of target genes were measured by real-time PCR and normalized by the average of the housekeeping genes $\beta$-actin and GAPDH. The results, mean \pm SEM of 8-12 mice/group, are expressed as fold induction over control group. Means in a row without a common letter differ, $P<0.05$ (ANOVA followed by LSD test)

regulatory element-binding factor 1 (SREBP-1c) $(P<0.05)$ with respect to both control and CLA1 group (Fig. 1a). Animals receiving a high-fat diet (Exp2) showed an increase in acetyl-Coenzyme A carboxylase alpha (Acc1) $(P<0.01)$ with the highest dose of CLA respect to the control group (Fig. 1b).

Modulation of fate of cellular fatty acids by CLA supplementation

We next studied the mRNA expression levels of the enzymes: diacylglycerol O-acyltransferase 2 (Dgat2) and 
Table 2 Relative changes in the expression of genes encoding transcription factors and co-activators, myogenic markers, and proteins involved in substrate handling and energy metabolism in gastrocnemius muscle of mice treated with CLA and fed a high-fat diet

\begin{tabular}{|c|c|c|c|}
\hline \multicolumn{4}{|c|}{ Experiment 2 (high-fat diet) } \\
\hline & Control & CLA3 & CLA4 \\
\hline \multicolumn{4}{|c|}{ Transcriptional co-activators } \\
\hline PGC- $1 \alpha$ & $1.00 \pm 0.05$ & $1.00 \pm 0.05$ & $1.05 \pm 0.05$ \\
\hline PGC $-1 \beta$ & $1.00 \pm 0.12$ & $1.13 \pm 0.10$ & $1.01 \pm 0.12$ \\
\hline \multicolumn{4}{|c|}{ Contractility/myogenic markers } \\
\hline MyHC-b & $1.00 \pm 0.08$ & $0.95 \pm 0.07$ & $0.87 \pm 0.08$ \\
\hline MyHC-IIa & $1.00 \pm 0.09$ & $1.07 \pm 0.05$ & $1.08 \pm 0.07$ \\
\hline MyHC-IIb & $1.00 \pm 0.12$ & $1.26 \pm 0.10$ & $1.14 \pm 0.05$ \\
\hline MyHC-IIx/d & $1.00 \pm 0.07$ & $0.88 \pm 0.03$ & $0.88 \pm 0.05$ \\
\hline \multicolumn{4}{|c|}{ Transcription factors } \\
\hline $\mathrm{ERR} \alpha$ & $1.00 \pm 0.02$ & $0.89 \pm 0.06$ & $0.87 \pm 0.05$ \\
\hline $\operatorname{PPAR} \alpha$ & $1.00 \pm 0.08$ & $1.06 \pm 0.07$ & $1.05 \pm 0.09$ \\
\hline $\operatorname{PPAR} \delta$ & $1.00 \pm 0.04$ & $1.02 \pm 0.06$ & $1.04 \pm 0.06$ \\
\hline \multicolumn{4}{|c|}{ Fatty acid metabolism } \\
\hline $\mathrm{Cd} 36$ & $1.00 \pm 0.06$ & $1.05 \pm 0.07$ & $0.99 \pm 0.06$ \\
\hline Lpl & $1.00 \pm 0.10$ & $0.96 \pm 0.07$ & $1.03 \pm 0.04$ \\
\hline Cpt1b & $1.00 \pm 0.04$ & $0.94 \pm 0.03$ & $0.93 \pm 0.04$ \\
\hline Acox 1 & $1.00 \pm 0.05$ & $0.98 \pm 0.04$ & $0.96 \pm 0.03$ \\
\hline MCAD & $1.00 \pm 0.08$ & $0.96 \pm 0.06$ & $1.08 \pm 0.04$ \\
\hline Fabp4 & $1.00 \pm 0.04^{\mathrm{a}}$ & $0.90 \pm 0.06^{\mathrm{a}}$ & $1.24 \pm 0.07^{\mathrm{b}}$ \\
\hline \multicolumn{4}{|c|}{ Glucose and insulin metabolism } \\
\hline Glut4 & $1.00 \pm 0.06$ & $0.90 \pm 0.05$ & $0.89 \pm 0.03$ \\
\hline Pdk4 & $1.00 \pm 0.04$ & $0.89 \pm 0.05$ & $0.84 \pm 0.06$ \\
\hline Hexokinase 2 & $1.00 \pm 0.08$ & $1.05 \pm 0.06$ & $1.02 \pm 0.03$ \\
\hline Insr & $1.00 \pm 0.05^{\mathrm{a}}$ & $0.78 \pm 0.06^{\mathrm{b}}$ & $0.75 \pm 0.03^{\mathrm{b}}$ \\
\hline \multicolumn{4}{|c|}{ Energy expenditure } \\
\hline Ucp3 & $1.00 \pm 0.05$ & $0.90 \pm 0.09$ & $0.90 \pm 0.05$ \\
\hline
\end{tabular}

RNA was isolated from gastrocnemius muscle of animals fed a highfat diet and receiving an oral dose of CLA ( $3 \mathrm{mg} /$ day in CLA 3 and $6 \mathrm{mg} /$ day in CLA4) for 30 days and double amount since then and for 35 days. Expression levels of target genes were measured by realtime PCR and normalized by the average of the housekeeping genes $\beta$-actin and GAPDH. The results, mean \pm SEM of 5-8 mice/group, are expressed as fold induction over control group. Means in a row without a common letter differ, $P<0.05$ (ANOVA followed by LSD test)

serine palmitoyltransferase (Sptlc1 and Sptlc2 units) involved in catalyzing the final step of triglyceride synthesis and controlling de novo ceramide synthesis, respectively (Fig. 2a, b). In Exp1, CLA supplementation did not affect the expression of Dgat2, whereas Sptlc1 mRNA levels were lower in CLA-treated groups $(P<0.01)$. Spctlc2 mRNA levels decreased after CLA supplementation, but just the highest dose (CLA2 group) was statistically different from the control group $(P<0.05)$. Conversely, we observed a reduction in the
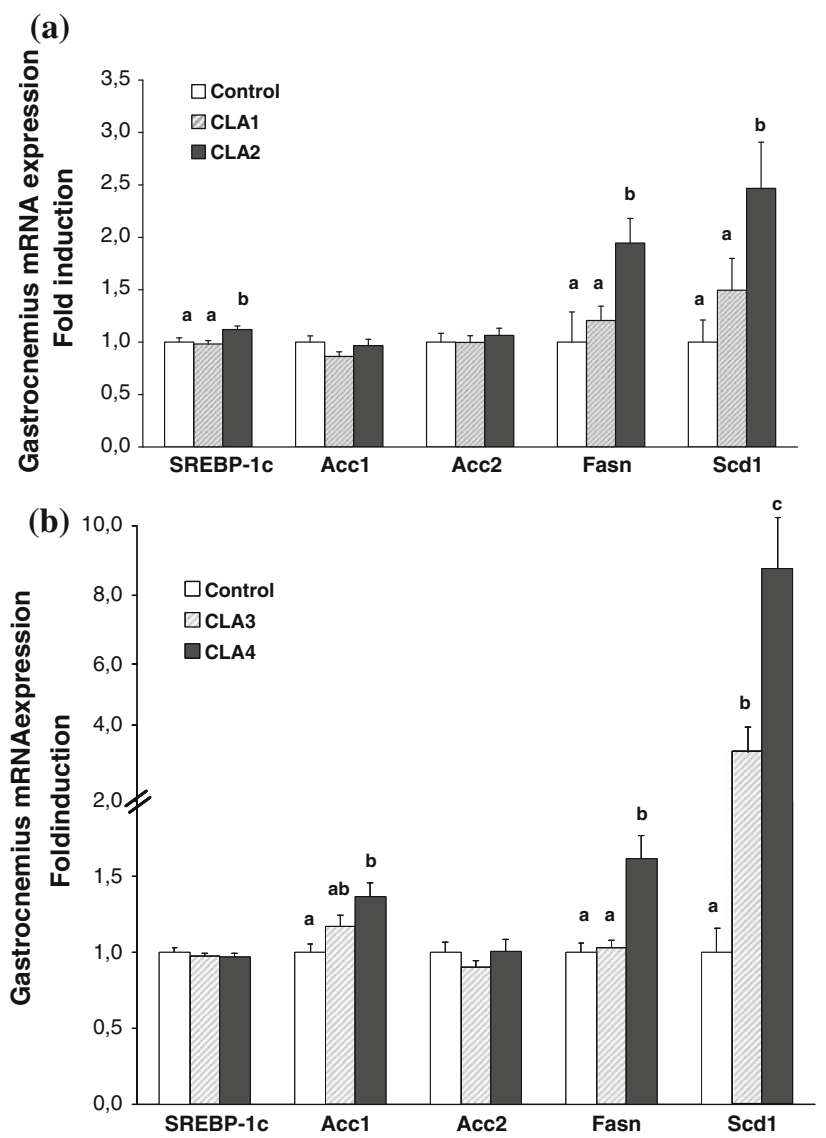

Fig. 1 Effects of CLA on lipogenic gene expression in gastrocnemius muscle. a In Exp1, mice were fed a standard-fat diet and received a daily dose of CLA equivalent to $3 \mathrm{mg}$ CLA/animal in CLA1 group and $6 \mathrm{mg} /$ animal in CLA2 group for 37 days. b In Exp2, mice were fed a high-fat diet and received a daily dose of CLA equivalent to $3 \mathrm{mg}$ CLA/animal in CLA3 group and $6 \mathrm{mg} /$ animal in CLA4 group for the first 30 days and $6 \mathrm{mg}$ CLA/animal in CLA3 group and $12 \mathrm{mg} /$ animal in CLA4 group for the additional 35 days of treatment. Data are mean \pm SEM of 8-12 mice in Exp1 and 5-8 mice in Exp2. Mean values with unlike letters are significantly different $(P<0.05)$; ANOVA followed by LSD test

mRNA levels of Dgat2 in CLA-treated groups in Exp2 $(P<0.05)$, which was accompanied by maintenance of Sptlc1 expression and an increase in mRNA levels of Sptlc2, reaching statistical significance with the highest dose $(P<0.01)$, in comparison with the control group.

Gene expression profile of endoplasmic reticulum stress markers by CLA supplementation in gastrocnemius muscle

Expression of key markers indicated that CLA was associated with the protection of endoplasmic reticulum (ER) stress in muscle. Transcript levels of X-box binding protein 1 (Xpb1) and the spliced form (Xpb1s) decreased in the CLA2 group in Exp1 $(P<0.05$ with respect to control group) (Fig. 3a). Xpb1s mRNA levels also decreased in 
(a)

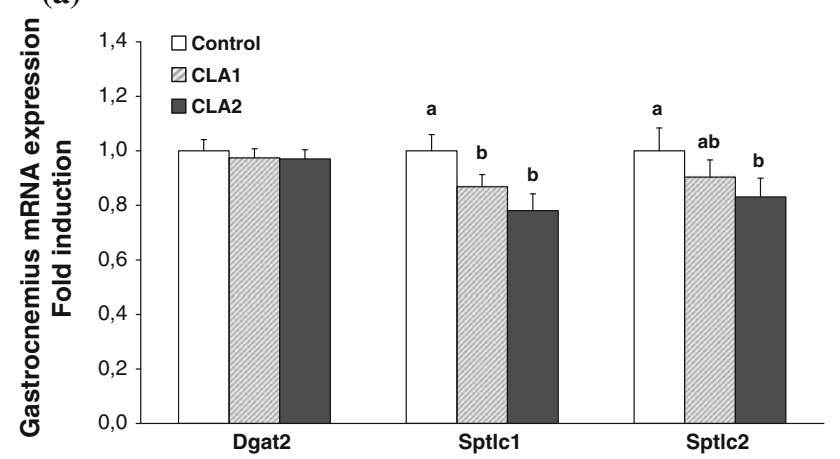

(b)

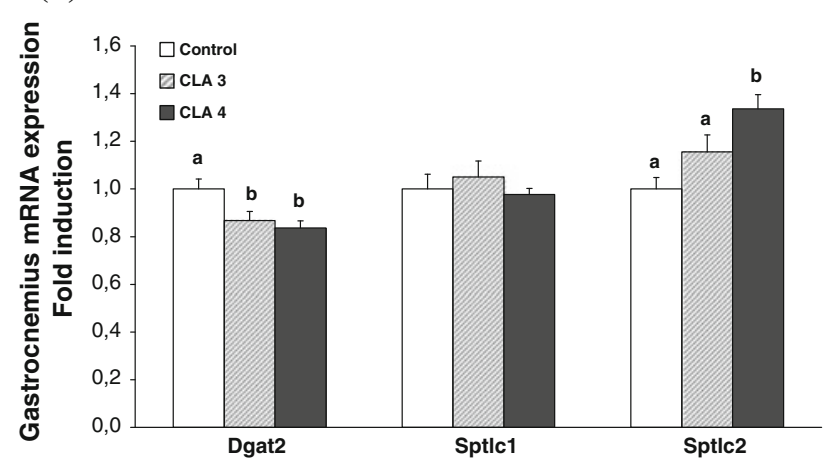

Fig. 2 Effect of CLA on transcriptional expression of enzymes associated with the fate of cellular fatty acids. a In Exp1, mice were fed a standard-fat diet and received a daily dose of CLA equivalent to $3 \mathrm{mg}$ CLA/animal in CLA1 group and $6 \mathrm{mg} / \mathrm{animal}$ in CLA2 group for 37 days. b In Exp2, mice were fed a high-fat diet and received a daily dose of CLA equivalent to $3 \mathrm{mg}$ CLA/animal in CLA3 group and $6 \mathrm{mg} / \mathrm{animal}$ in CLA4 group for the first 30 days and $6 \mathrm{mg} \mathrm{CLA} /$ animal in CLA3 group and $12 \mathrm{mg} / \mathrm{animal}$ in CLA4 group for the additional 35 days of treatment. Data are mean \pm SEM of 7-12 mice in Exp1 and 6-8 mice in Exp2. Mean values with unlike letters are significantly different $(P<0.05)$; ANOVA followed by LSD test

CLA4 group in Exp2 $(P<0.01$ with respect to control group) (Fig. 3b). This was accompanied by a slight yet not statistically significant decrease in activating transcription factor 3 (Atf3) and in DNA damage-inducible transcript 3 (CHOP) mRNA levels in all the groups treated with CLA, irrespective of the diet (Fig. 3a, b, under standard- and high-fat diet, respectively).

Correlation between the induction of Scd1 and fatty acid metabolism markers

We further analyzed whether Scd1 induction was part of a coordinated pattern of gene expression, linking fatty acid metabolism and stress in ER. High correlations were found between the expression of Scd1 and Fasn in both experimental designs (Table 3, $r=0.593(P<0.01)$ in Exp1 and $r=0.809(P<0.01)$ in Exp2), suggesting a coordinated action on the synthesis and desaturation of fatty acids. In Exp2, the high induction of Scd1 correlated also with the
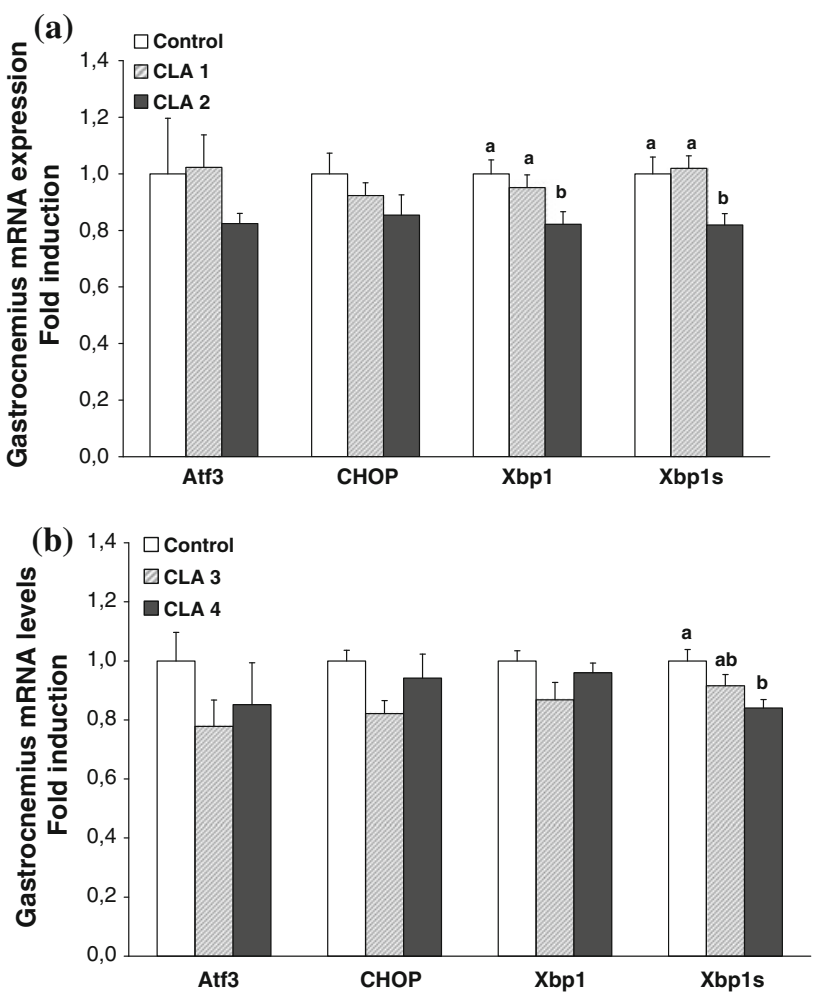

Fig. 3 Effect of CLA on gene expression of markers of endoplasmic reticulum stress in gastrocnemius muscle. a In Exp1, mice were fed a standard-fat diet and received a daily dose of CLA equivalent to $3 \mathrm{mg}$ CLA/animal in CLA1 group and $6 \mathrm{mg} / \mathrm{animal}$ in CLA2 group for 37 days. b In Exp2, mice were fed a high-fat diet and received a daily dose of CLA equivalent to $3 \mathrm{mg}$ CLA/animal in CLA3 group and $6 \mathrm{mg} / \mathrm{animal}$ in CLA4 group for the first 30 days and $6 \mathrm{mg}$ CLA/ animal in CLA3 group and $12 \mathrm{mg} / \mathrm{animal}$ in CLA4 group for the additional 35 days of treatment. Data are mean \pm SEM of 7-12 mice in Exp1 and 8 mice in Exp2. Mean values with unlike letters are significantly different $(P<0.05)$; ANOVA followed by LSD test

increased expression of Fabp4 $(r=0.544, P<0.01)$, which could bind and contribute to efficient handling of the saturated and unsaturated fatty acids produced in these circumstances.

Interestingly, the high induction of Scd1 correlated negatively with the expression of ER stress markers Xbp1/Xbp1s and CHOP $(r=-0.384, P<0.05$ for Xbp1 and $r=-0.624, P<0.01$ for CHOP in Exp1, and $r=$ $-0.476, P<0.05$ for Xbp1s in Exp2). In addition, in Exp2, induction of Scd1 inversely correlated with the expression of InsR $(r=-0.454, P<0.05)$.

Furthermore, Scd1 expression was found to be inversely correlated to Sptlc2, depending on the experimental setup; that is, negatively correlated in $\operatorname{Exp} 1 \quad(r=-0.450$, $P<0.05)$ and positively correlated in $\operatorname{Exp} 2(r=0.664$, $P<0.01$ ), suggesting a differential effect of CLA depending on the dietary regime. In order to clarify this aspect, we analyzed the correlations between the expression of Sptlc (units 1 and 2) and the markers of ER stress 
Table 3 Correlations between expression of Scd1 and markers of fatty acid metabolism, ER stress, and insulin receptor in mice supplemented with CLA and fed either a standard (Exp1) or a high-fat diet (Exp2)

\begin{tabular}{llllllll}
\hline & Fasn & Fabp4 & Sptlc2 & Xbp1 & Xbp1s & CHOP & InsR \\
\hline Scd1 & & & & & & \\
Exp1 & $0.593^{* *}$ & 0.063 & $-0.450^{*}$ & $-0.384^{*}$ & -0.324 & $-0.624^{* *}$ \\
Exp2 & $0.809^{* *}$ & $0.544^{* *}$ & $0.664^{* *}$ & -0.110 & $-0.476^{*}$ & -0.069 & -0.002 \\
\hline
\end{tabular}

The correlations were assessed by the Pearson $\chi^{2}$ test. Statistical significance (2-tailed), $* P<0.05$, ** $P<0.01$

(Table 4). We found that the expression of Sptlc1 correlated positively with the expression of Sptlc2 $(r=0.599$, $P<0.01)$, Xbp1 $(r=0.437, \quad P<0.05)$, and Xbp1s $(r=0.582, P<0.01)$ in Exp1 but only with Xbp1s $(r=0.583, P<0.01)$ in Exp2. Whereas expression of Sptlc2 correlated positively with Xbp1 $(r=0.399$, $P<0.05)$, Xbp1s $(r=0.471, P<0.05)$, and CHOP $(r=0.399, P<0.05)$ in Exp1, and no statistically significant correlations were found for these markers in Exp2.

\section{Effects of CLA in $\mathrm{C} 2 \mathrm{C} 12$ cells}

Differentiated myotubes incubated with doses of CLA ranging from 5 to $150 \mu \mathrm{M}$ for $24 \mathrm{~h}$ did not show significant changes in mRNA levels of SREBP-1c, Fasn, or Scd1 (Online Resource 2). However, through the different cell culture experiments, we observed a slight (around 20\%) but consistent increase in Scd1 transcriptional expression with both 10 and $20 \mu \mathrm{M}$ CLA, which attained statistical significance when the whole set of data from all the experiments was considered (two experiments for $10 \mu \mathrm{M}$ CLA and three for $20 \mu \mathrm{M}$ CLA) $(1.00 \pm 0.05$ for the control versus $1.21 \pm 0.08$ for the CLA $10 \mu \mathrm{M}, P<0.05$; and $1.00 \pm 0.03$ for the control versus $1.20 \pm 0.06$ for the CLA $20 \mu \mathrm{M}, P<0.01$; Student's $t$ test). Furthermore, mRNA expression of Fasn and Scd1 did not change with lower incubation periods (2, 6 or $8 \mathrm{~h}$ ) with $20 \mu \mathrm{M}$ CLA, or after $48 \mathrm{~h}$ with 10 or $20 \mu \mathrm{M}$ CLA (data not shown).

We next explored whether exposure to CLA would prevent palmitate-induced increase in ER stress marker expression (Fig. 4). However, mRNA levels of Atf3, CHOP, and $\mathrm{Xbp} 1 \mathrm{~s}$ in cells co-incubated with palmitate $(0.5 \mathrm{mM})$ and CLA $(20 \mu \mathrm{M})$ were higher than those observed with palmitate alone (Fig. 4a-c). Xpb1s increase was accompanied by a decrease in Xbp1 expression that was more pronounced with the combined treatment of CLA and palmitate (Fig. 4d). Co-incubation with insulin (100 nM) did not change the expression profile of ER stress markers observed with palmitate and/or CLA treatment (Fig. 4).

Fasn and Scd1 expression in cultured myotubes were studied under induction of ER stress by palmitate (Fig. 5). Insulin, irrespective of the presence of CLA, increased mRNA levels of Fasn and Scd1 in accordance with its known anabolic role. A decrease in the expression of both
Table 4 Correlations between the markers of ceramide synthesis and ER stress in mice supplemented with CLA and fed either a standard(Exp1) or a high-fat diet (Exp2)

\begin{tabular}{lllll}
\hline & Sptlc2 & Xbp1 & Xbp1s & CHOP \\
\hline Sptlc1 & & & & \\
Exp1 & $0.599 * *$ & $0.437^{*}$ & $0.582^{* *}$ & 0.170 \\
Exp2 & 0.362 & 0.340 & $0.583^{* *}$ & 0.296 \\
Sptlc2 & & & & \\
Exp1 & - & $0.399^{*}$ & $0.471^{*}$ & $0.399^{*}$ \\
Exp2 & - & 0.128 & -0.136 & 0.203 \\
\hline
\end{tabular}

The correlations were assessed by the Pearson $\chi^{2}$ test. Statistical significance (2-tailed), $* P<0.05, * * P<0.01$

genes was observed in cells treated with palmitate, counteracting the induction of insulin. Furthermore, Scd1 decrease was even more pronounced in cells co-incubated with palmitate and CLA, irrespective of the presence of insulin (Fig. 5).

\section{Discussion}

In previous studies, we have shown that moderate doses of CLA are able to decrease body fat accumulation and modulate the inflammatory profile of adipose tissue with a minor impact on insulin sensitivity in mice (Parra et al. 2010a, b). In this paper, our interest was to assess whether skeletal muscle could be a target tissue of CLA action, actively involved in the body fat-lowering effect of CLA as observed in our previous studies. Searching for potential underlying molecular mechanisms, we analyzed the gene expression of markers involved in glucose and lipid homeostasis following the same experimental design, that is, mice supplemented with moderate doses of isomers mix of CLA under either standard- or high-fat diet.

PGC- $1 \alpha$ and PGC- $1 \beta$ are members of a small family of transcriptional co-activators that influence metabolic pathways in muscle and other tissues by co-activating a number of transcription factors including $\operatorname{PPAR} \gamma, \operatorname{PPAR} \alpha$, and ERR $\alpha$. Although an increase in PGC- $1 \beta$ induced by CLA treatment in standard-fat diet conditions was found, no impact on the expression of the associated transcription factors was observed. As recent studies in rodents suggest 

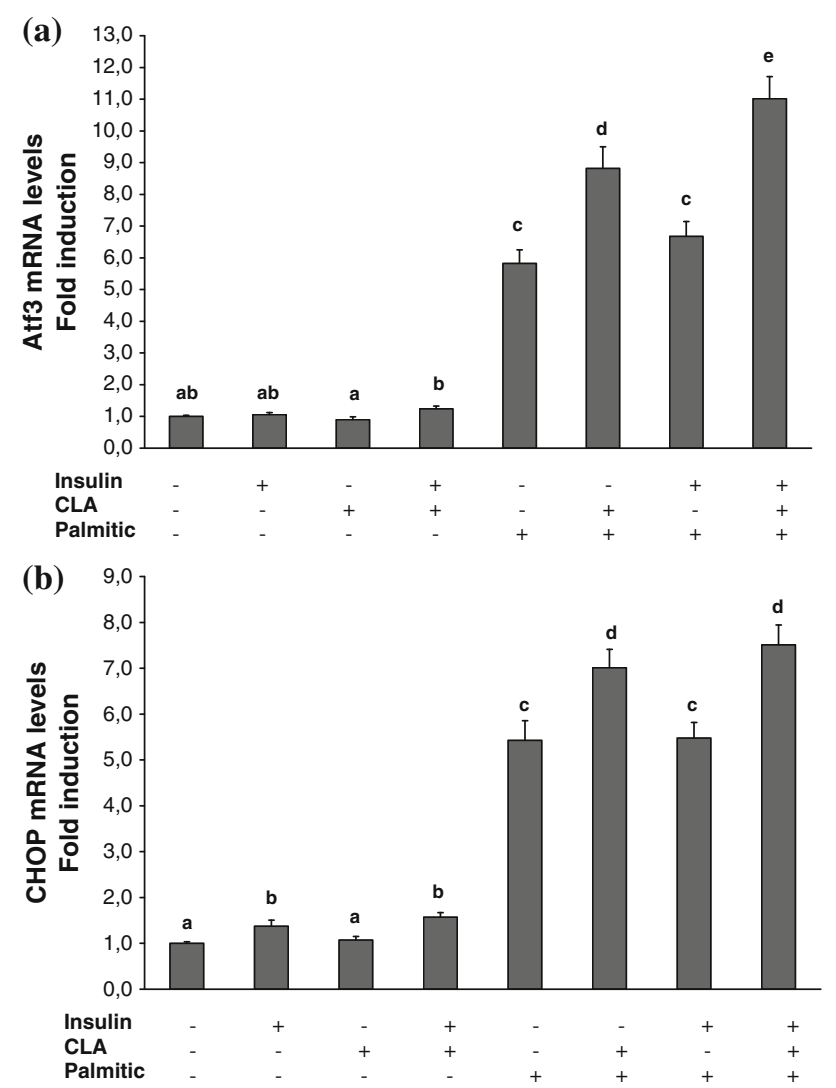

(c)
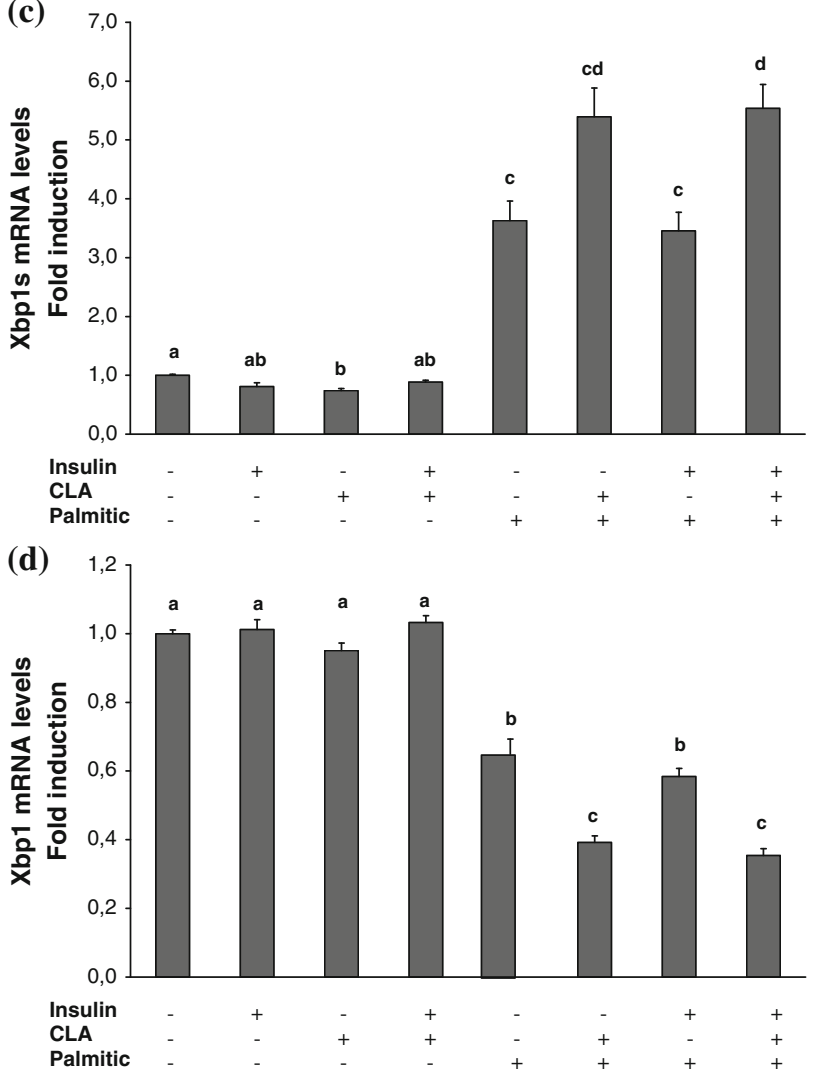

4 Fig. 4 Potential effect of CLA to counteract expression of endoplasmic reticulum stress markers induced by palmitic acid in $\mathrm{C} 2 \mathrm{C} 12$ myotubes. Fully differentiated myotubes were incubated at day 9 with a CLA mixture $(20 \mu \mathrm{M})$ and/or palmitic acid $(0.5 \mathrm{mM})$, in the absence or in the presence of insulin $(100 \mathrm{nM})$ for $24 \mathrm{~h}$ in serum-free differentiation media. CLA mixture was an equimolar solution (50:50) of both active isomers trans-10, cis-12 and cis-9, trans-11 CLA. The ER stress markers analyzed are Atf3 (a), CHOP (b), Xbp1s (c), and $\mathrm{Xbp} 1$ (d). Data are expressed as mean \pm SEM of three independent experiments ( $n=4-5$ data in each experiment). Mean values with unlike letters are significantly different $(P<0.05)$; ANOVA followed by LSD test

that PGC- $1 \alpha$ and PGC- $1 \beta$ influence the composition of fiber types in skeletal muscle (Arany et al. 2007; Mortensen et al. 2006), we explored this possibility. However, analysis of gene expression of myosin heavy-chain isoforms did not show any effect of CLA on its composition, irrespective of the type of diet (Tables 1 and 2).

Although there is still limited evidence (Park et al. 1997; Rahman et al. 2001; Zabala et al. 2006), enhanced fat transport and oxidation into skeletal muscle have been proposed as the mechanism responsible for CLA-induced changes in body composition. In neither of our experimental conditions did we observe any major changes in gene expression of fatty acid transport or oxidation-related proteins or in key regulators of lipid and carbohydrate metabolism. Thus, transcriptional results, a priori, did not support an enhancement of $\beta$-oxidation in skeletal muscle contributing to the antiobesity effect of CLA observed.

By contrast, and unexpectedly, a set of genes classically involved in lipogenesis were significantly activated by CLA treatment. Muscle is not usually considered a lipogenic tissue, but some evidence suggests that de novo lipogenesis can indeed take place in muscle and be modulated by factors influencing nutritional status (Aas et al. 2004; Guillet-Deniau et al. 2004). In our experimental conditions, Acc1, which is the isoform that synthesizes the pool of malonyl-CoA that is used for de novo lipogenesis, was increased in Exp2 and not affected in Exp1 by CLA supplementation, whereas the expression of SREBP-1c, which is a master regulator of lipogenic/glycolitic genes, was increased in Exp1 by CLA. In accordance with this profile, Acc2, which is expressed in "nonlipogenic" tissues such as skeletal and cardiac muscle and is thought to control the pool of malonyl-CoA that regulates fatty acid oxidation, was unaltered in both situations (Fig. 1).

In addition to the above, a high impact of CLA was observed on two classical lipogenic enzymes, Fasn and Scd1. The effect of CLA increasing Fasn (up to twofold induction) and mostly Scd1 (up to 8.6-fold) gene expression is a consistent effect, common to both experimental conditions, although the increase in Scd1 was more pronounced in Exp2 (high-fat feeding, Fig. 1b) than in Exp1 (standard-fat feeding, Fig. 1a). Similarly, in a previous 

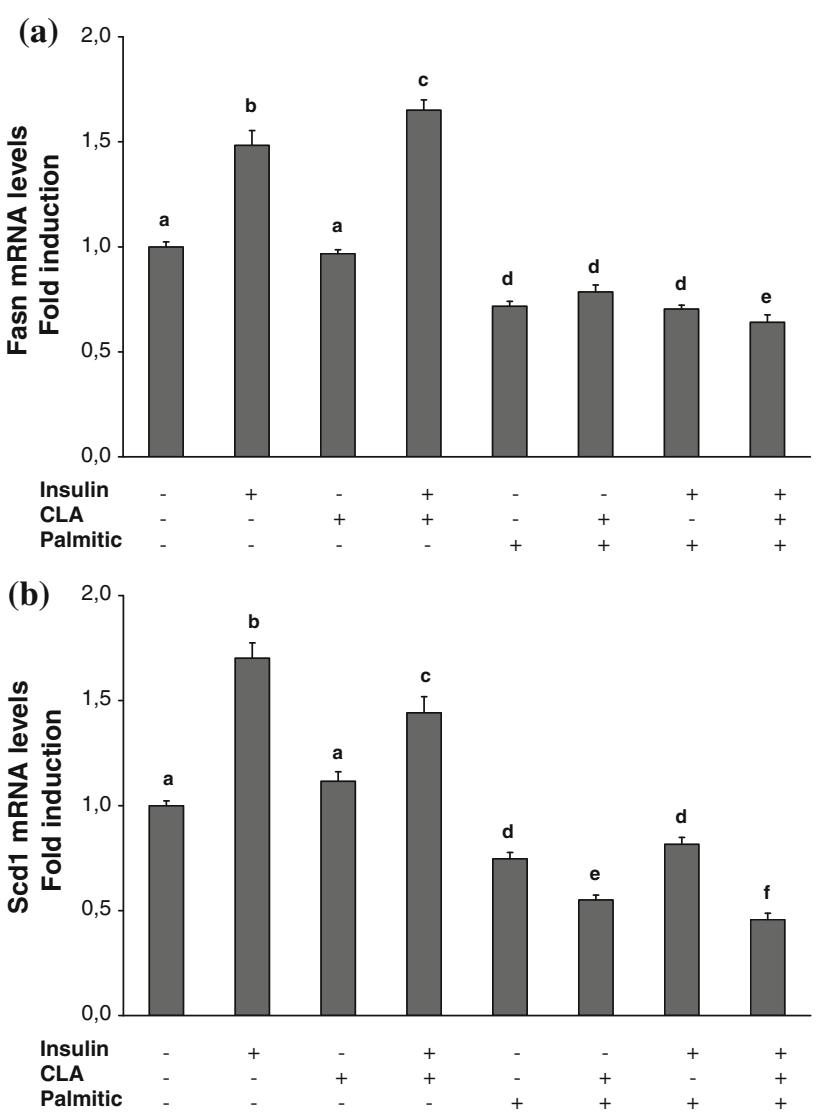

Fig. 5 Effect of CLA on Fasn and Scd1 gene expression in C2C12 myotubes under conditions inducing expression of markers of ER stress. Fully differentiated myotubes were incubated at day 9 with a CLA mixture $(20 \mu \mathrm{M})$ and/or palmitic acid $(0.5 \mathrm{mM})$, in the absence or in the presence of insulin $(100 \mathrm{nM})$ for $24 \mathrm{~h}$ in serum-free differentiation media. CLA mixture was an equimolar solution (50:50) of both active isomers trans-10, cis-12 and cis-9, trans-11 CLA. Fasn (a) and Scd1 (b) data are expressed as mean \pm SEM of three independent experiments yielding essentially the same results ( $n=4-5$ in each experiment). Mean values with unlike letters are significantly different $(P<0.05)$; ANOVA followed by LSD test

study conducted in our laboratory, a tendency to increase Scd1 expression in mice treated with $3 \mathrm{mg}$ CLA/day for just 9 days was also observed, and this was more pronounced in animals previously fed for 1 month with a cafeteria diet (a palatable, hypercaloric diet) compared with those fed with a standard-fat diet (unpublished data). These results suggest that conditions (metabolic status of the animals, diet composition, duration of treatment, and doses of CLA) are able to modulate the impact of CLA on activation of lipogenic genes in skeletal muscle. In fact, other, still uncharacterized, factors must contribute to this profile, because Fasn and Scd1 mRNA levels were not induced to this extent in $\mathrm{C} 2 \mathrm{C} 12$ cell cultures. Although cells were treated with different doses of CLA and for different periods of time, only a slight increase in Scd1 was consistently found with 10 and $20 \mu \mathrm{M}$ CLA dose (Online Resource 2).
Studies concerning the effect of CLA on Scd1 transcriptional expression and/or activity in muscle are scarce (Demaree et al. 2002; Kang et al. 2004), and those conducted in liver and adipose tissue, or even in cell cultures, give conflicting results (Choi et al. 2000; Kang et al. 2004; Lee et al. 1998; Park et al. 2000; Peters et al. 2001). To our knowledge, this is the first time that such an increase in Scd1 expression by CLA mixture has been described in normal mice. In fact, the trans-10, cis-12, but not cis-9, trans-11 CLA isomer, has been used as an inhibitor of Scd1 in some studies (Busch et al. 2005; Wei et al. 2007).

Scd1 is an endoplasmic reticulum-bound desaturase that catalyzes the conversion of saturated fatty acids into monounsaturated fatty acids. The classical view of this enzymatic activity states that the quantity and distribution of saturated and unsaturated fatty acids affect many cellular processes, including membrane fluidity, the generation of second messengers in signalling cascades, metabolic fuel storage in the form of triacylglycerols, cellular differentiation, and apoptosis (Hulbert et al. 2005; Scaglia and Igal 2005). Mice lacking Scd1 are protected from obesity and insulin resistance and are characterized by decreased fatty acid synthesis and increased fatty acid oxidation (Cohen et al. 2002; MacDonald et al. 2008; Ntambi et al. 2002). Therefore, the weight of experimental evidence from knock-out models suggests that Scd1, mainly in liver and adipose tissue, could contribute to the pathogenesis of obesity and insulin resistance. On the other hand, recent evidence suggests a beneficial role of increased skeletal muscle Scd1 in human obesity (Peter et al. 2009). Scd1 could act by suppressing the cellular deleterious effects of saturated fatty acids (Borradaile et al. 2006; Peter et al. 2008; Pinnamaneni et al. 2006). Saturated fatty acids, particularly stearate and palmitate, have a strong lipotoxic potential to induce inflammation, insulin resistance, and ER stress in many cell types (Borradaile et al. 2006; Coll et al. 2008; Moffitt et al. 2005; Staiger et al. 2006).

Because of its role in post-translational protein modification and lipid synthesis, ER is viewed as a "nutrientsensing" apparatus, sensitive to a variety of environmental signals. Therefore, ER stress is emerging as a potential link between inflammation and metabolic disease (Hotamisligil 2010). ER stress activates the unfolded protein response pathway in order to restore ER homeostasis and circumvent cell death, this includes the splicing of Xbp1 mRNA and the transcriptional activation of CHOP and Atf3 (Hotamisligil 2010; Peter et al. 2009). An interesting link with the activation of Scd1 by CLA is that induction of ER stress markers by palmitate is completely prevented by Scd1 overexpression (Peter et al. 2009), while loss or reduction in Scd1 increases ER stress. Therefore, the activation of Fasn and Scd1 in muscle of CLA supplemented animals could be seen as a way to efficiently counteract stress in ER 
that could be induced, particularly in high-fat feeding animals. Additionally, the study of correlations that was performed on gene expression points to a concerted action between the induction of Scd1 and the reduction in the expression of ER stress markers. Unfortunately, we could not reproduce these effects in $\mathrm{C} 2 \mathrm{C} 12$ cell cultures; induction of ER stress markers (Atf3, CHOP and XBP1s) by palmitate was not prevented by CLA treatment but even enhanced; probably because in cell cultures, we were not able to mimic the conditions that elicited a strong induction of Scd1 by CLA in vivo (around ninefold induction) and only attained a modest 1.2 -fold induction in vitro.

In addition, expression of genes associated with the fate of cellular fatty acids (Dgat2, Sptlc1, and Spltc2) suggested a different scenario when the two dietary regimens (Exp1 and Exp2) were compared. Under standard-diet feeding (Exp1), increased Scd1 gene expression was accompanied by the mRNA decrease in rate-limiting enzymes of de novo ceramide synthesis, Sptlc1 and Spltc2, keeping the potential partitioning of fatty acids toward triglyceride synthesis. Whereas under high-fat diet (Exp2), although no changes in the expression of Sptlc1 were found, increased Spltc2 was observed (at the highest dose of CLA). This was accompanied by a decrease in Dgat2, the enzyme that catalyzes the final reaction in the synthesis of triglycerides from diacylglycerol, suggesting a potential incorporation of fatty acids in other lipid species, such as ceramides and/or specific sphingolipids.

Ceramide accumulation is considered a potential mediator of insulin resistance and lipotoxicity (Chavez et al. 2003; Summers 2006). In this sense, recent studies reported beneficial effects on glucose tolerance and insulin resistance with the prevention of de novo ceramide synthesis (Ussher et al. 2010; Yang et al. 2009). In the present experimental conditions, muscle Scd1 overexpression may contribute to attenuation of ceramide and diacylglycerol accumulation, which protects myotubes from fatty acidinduced insulin resistance (Pinnamaneni et al. 2006), particularly under standard-fat feeding (Exp1). However, under high-fat feeding, the role of the activation of Sptlc2 may not necessarily be negative, and it was not accompanied by induction of ER stress and even the correlations with the stress markers found in Exp1 disappeared in Exp2; thus, potentiating synthesis of specific lipids may be an additional output in this scenario contributing to the fatlowering effect of CLA (Fig. 6).

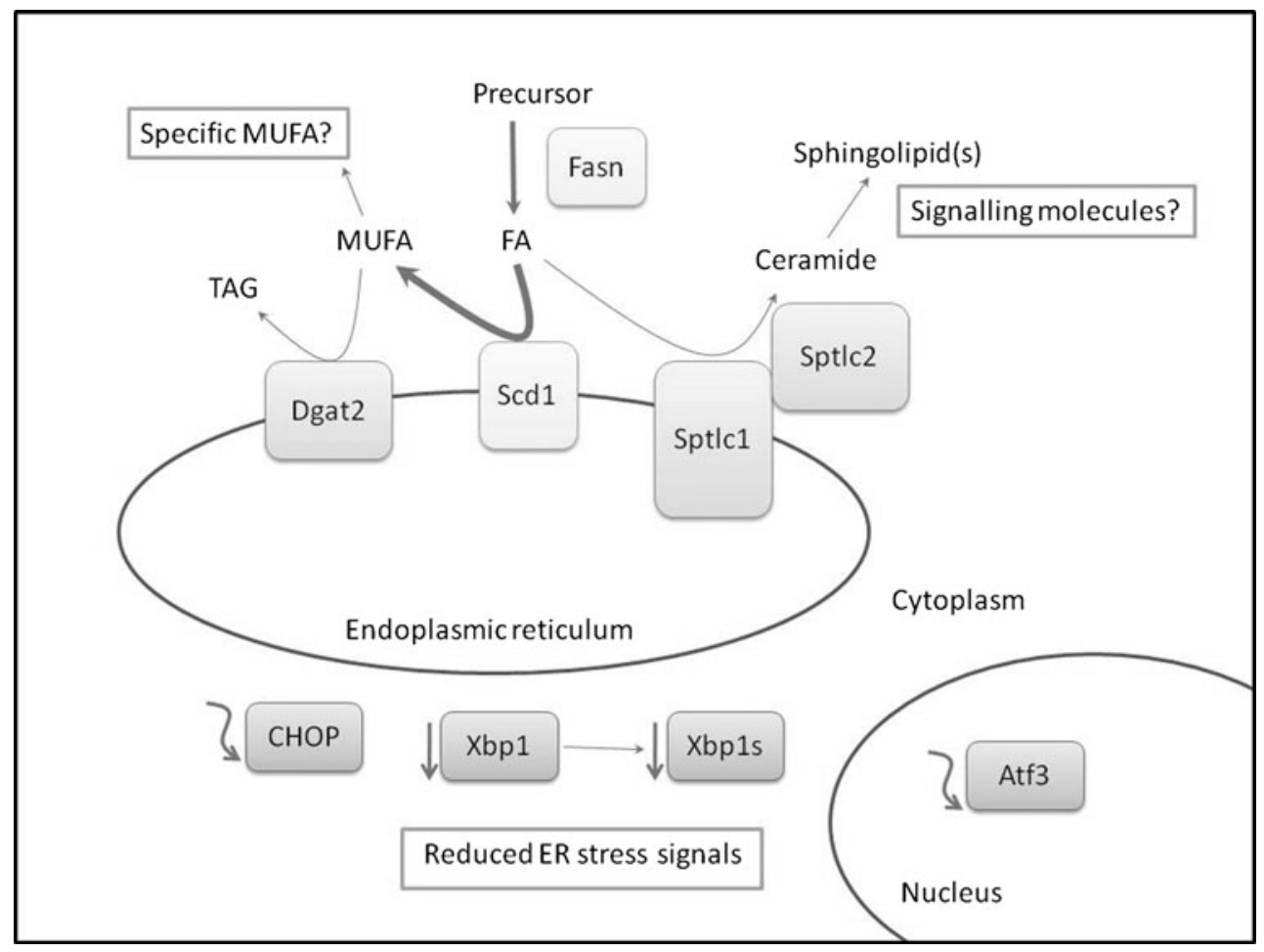

Fig. 6 Schematic representation of the molecular effects of CLA on skeletal muscle. Induction of Scd1, a ER-bound enzyme, is the key point in the molecular mechanism of action of CLA in muscle. It is suggested a coordinated regulation of the expression of the genes represented. Fasn would drive fatty acids to Scd1 for unsaturation, which is enhanced by CLA. Then, dgat 2 and Sptlc1 and 2, would be coordinated for the fate of these fatty acids toward the synthesis of triglycerides or specific sphingolipids, maybe acting as secondary signalling molecules. These molecular events are associated with a protective of role of stress in ER, because the mediators of ER stress signalling pathways, including UPR (unfolded protein response) and apoptosis markers, are decreased or not altered. FA, fatty acid; MUFA, monounsaturated fatty acid; TAG: triacylglycerol 
Finally, induction of muscle Scd1 by moderate doses of CLA that are effective in reducing body fat content in mice opens a new perspective for research in light of the recent finding in germline-less $C$. elegans. A very interesting paper has nicely demonstrated extension of lifespan in this animal model (Goudeau et al. 2011). This is mediated through the induction of NHR-80, a transcription factor that specifically targets activation of fat-6, a fatty acid desaturase, having the functional role of Scd in mammalian organisms (Brock et al. 2006). We do not know whether the same output is present with the moderate doses of CLA in our experimental design, but it is an interesting aspect to be considered in future research.

In summary, the transcriptomic analysis of key skeletal muscle genes suggests that enhancement of fatty acid oxidation does not contribute to the fat-lowering effect of moderate doses of CLA supplementation seen in standardfat and high-fat fed mice, but it is clear that the high induction of Scd1 (almost ninefold) by CLA in skeletal muscle is a novel finding, initially associated with a protective role, since markers of ER stress were decreased in CLA-supplemented animals. However, we may not discard other specific effects (i.e., on life expectancy), and next steps should undertake further characterization of the metabolic product(s), its metabolic fate, and biological/ functional impact.

Acknowledgments This work was supported by the grant AGL200911277 from the Spanish Government and the European project BIOCLAIMS (FP7-244995). CIBER-OBN de Fisiopatología de la Obesidad y Nutrición is an initiative from ISCIII.

\section{References}

Aas V, Kase ET, Solberg R, Jensen J, Rustan AC (2004) Chronic hyperglycaemia promotes lipogenesis and triacylglycerol accumulation in human skeletal muscle cells. Diabetologia 47: 1452-1461

Arany Z, Lebrasseur N, Morris C, Smith E, Yang W, Ma Y, Chin S, Spiegelman BM (2007) The transcriptional coactivator PGC1 beta drives the formation of oxidative type IIX fibers in skeletal muscle. Cell Metab 5:35-46

Benjamin S, Spener F (2009) Conjugated linoleic acids as functional food: an insight into their health benefits. Nutr Metab (Lond) $6: 36$

Borradaile NM, Han X, Harp JD, Gale SE, Ory DS, Schaffer JE (2006) Disruption of endoplasmic reticulum structure and integrity in lipotoxic cell death. J Lipid Res 47:2726-2737

Brock TJ, Browse J, Watts JL (2006) Genetic regulation of unsaturated fatty acid composition in C. elegans. PLoS Genet 2:e108

Busch AK, Gurisik E, Cordery DV, Sudlow M, Denyer GS, Laybutt DR, Hughes WE, Biden TJ (2005) Increased fatty acid desaturation and enhanced expression of stearoyl coenzyme A desaturase protects pancreatic beta-cells from lipoapoptosis. Diabetes 54:2917-2924
Chavez JA, Knotts TA, Wang LP, Li G, Dobrowsky RT, Florant GL, Summers SA (2003) A role for ceramide, but not diacylglycerol, in the antagonism of insulin signal transduction by saturated fatty acids. J Biol Chem 278:10297-10303

Choi Y, Kim YC, Han YB, Park Y, Pariza MW, Ntambi JM (2000) The trans-10, cis-12 isomer of conjugated linoleic acid downregulates stearoyl-CoA desaturase 1 gene expression in 3T3-L1 adipocytes. J Nutr 130:1920-1924

Cohen P, Miyazaki M, Socci ND, Hagge-Greenberg A, Liedtke W, Soukas AA, Sharma R, Hudgins LC, Ntambi JM, Friedman JM (2002) Role for stearoyl-CoA desaturase-1 in leptin-mediated weight loss. Science 297:240-243

Coll T, Eyre E, Rodriguez-Calvo R, Palomer X, Sanchez RM, Merlos M, Laguna JC, Vazquez-Carrera M (2008) Oleate reverses palmitate-induced insulin resistance and inflammation in skeletal muscle cells. J Biol Chem 283:11107-11116

DeLany JP, Blohm F, Truett AA, Scimeca JA, West DB (1999) Conjugated linoleic acid rapidly reduces body fat content in mice without affecting energy intake. Am J Physiol 276:R1172R1179

Demaree SR, Gilbert CD, Mersmann HJ, Smith SB (2002) Conjugated linoleic acid differentially modifies fatty acid composition in subcellular fractions of muscle and adipose tissue but not adiposity of postweaning pigs. J Nutr 132:3272-3279

Goudeau J, Bellemin S, Toselli-Mollereau E, Shamalnasab M, Chen Y, Aguilaniu H (2011) Fatty acid desaturation links germ cell loss to longevity through NHR-80/HNF4 in C. elegans. PLoS Biol 9:e1000599

Guillet-Deniau I, Pichard AL, Kone A, Esnous C, Nieruchalski M, Girard J, Prip-Buus C (2004) Glucose induces de novo lipogenesis in rat muscle satellite cells through a sterol-regulatoryelement-binding-protein-1c-dependent pathway. J Cell Sci 117: 1937-1944

Hotamisligil GS (2010) Endoplasmic reticulum stress and the inflammatory basis of metabolic disease. Cell 140:900-917

Hulbert AJ, Turner N, Storlien LH, Else PL (2005) Dietary fats and membrane function: implications for metabolism and disease. Biol Rev Camb Philos Soc 80:155-169

Kang K, Miyazaki M, Ntambi JM, Pariza MW (2004) Evidence that the anti-obesity effect of conjugated linoleic acid is independent of effects on stearoyl-CoA desaturase1 expression and enzyme activity. Biochem Biophys Res Commun 315:532-537

Kennedy A, Martinez K, Schmidt S, Mandrup S, LaPoint K, McIntosh M (2010) Antiobesity mechanisms of action of conjugated linoleic acid. J Nutr Biochem 21:171-179

Lee KN, Pariza MW, Ntambi JM (1998) Conjugated linoleic acid decreases hepatic stearoyl-CoA desaturase mRNA expression. Biochem Biophys Res Commun 248:817-821

MacDonald ML, Singaraja RR, Bissada N, Ruddle P, Watts R, Karasinska JM, Gibson WT, Fievet C, Vance JE, Staels B, Hayden MR (2008) Absence of stearoyl-CoA desaturase-1 ameliorates features of the metabolic syndrome in LDLRdeficient mice. J Lipid Res 49:217-229

Martin JC, Gregoire S, Siess MH, Genty M, Chardigny JM, Berdeaux O, Juaneda P, Sebedio JL (2000) Effects of conjugated linoleic acid isomers on lipid-metabolizing enzymes in male rats. Lipids 35:91-98

Moffitt JH, Fielding BA, Evershed R, Berstan R, Currie JM, Clark A (2005) Adverse physicochemical properties of tripalmitin in beta cells lead to morphological changes and lipotoxicity in vitro. Diabetologia 48:1819-1829

Mortensen OH, Frandsen L, Schjerling P, Nishimura E, Grunnet N (2006) PGC-1alpha and PGC-1beta have both similar and distinct effects on myofiber switching toward an oxidative phenotype. Am J Physiol Endocrinol Metab 291:E807-E816 
Ntambi JM, Miyazaki M, Stoehr JP, Lan H, Kendziorski CM, Yandell BS, Song Y, Cohen P, Friedman JM, Attie AD (2002) Loss of stearoyl-CoA desaturase-1 function protects mice against adiposity. Proc Natl Acad Sci USA 99:11482-11486

Park Y, Albright KJ, Liu W, Storkson JM, Cook ME, Pariza MW (1997) Effect of conjugated linoleic acid on body composition in mice. Lipids 32:853-858

Park Y, Storkson JM, Ntambi JM, Cook ME, Sih CJ, Pariza MW (2000) Inhibition of hepatic stearoyl-CoA desaturase activity by trans-10, cis-12 conjugated linoleic acid and its derivatives. Biochim Biophys Acta 1486:285-292

Parra P, Palou A, Serra F (2010a) Moderate doses of conjugated linoleic acid reduce fat gain, maintain insulin sensitivity without impairing inflammatory adipose tissue status in mice fed a highfat diet. Nutr Metab (Lond) 7:5

Parra P, Serra F, Palou A (2010b) Moderate doses of conjugated linoleic acid isomers mix contribute to lowering body fat content maintaining insulin sensitivity and a noninflammatory pattern in adipose tissue in mice. J Nutr Biochem 21:107-115

Peter A, Weigert C, Staiger H, Rittig K, Cegan A, Lutz P, Machicao F, Haring HU, Schleicher E (2008) Induction of stearoyl-CoA desaturase protects human arterial endothelial cells against lipotoxicity. Am J Physiol Endocrinol Metab 295:E339-E349

Peter A, Weigert C, Staiger H, Machicao F, Schick F, Machann J, Stefan N, Thamer C, Haring HU, Schleicher E (2009) Individual stearoyl-coa desaturase 1 expression modulates endoplasmic reticulum stress and inflammation in human myotubes and is associated with skeletal muscle lipid storage and insulin sensitivity in vivo. Diabetes 58:1757-1765

Peters JM, Park Y, Gonzalez FJ, Pariza MW (2001) Influence of conjugated linoleic acid on body composition and target gene expression in peroxisome proliferator-activated receptor alphanull mice. Biochim Biophys Acta 1533:233-242

Pinnamaneni SK, Southgate RJ, Febbraio MA, Watt MJ (2006) Stearoyl CoA desaturase 1 is elevated in obesity but protects against fatty acid-induced skeletal muscle insulin resistance in vitro. Diabetologia 49:3027-3037

Rahman SM, Wang Y, Yotsumoto H, Cha J, Han S, Inoue S, Yanagita T (2001) Effects of conjugated linoleic acid on serum leptin concentration, body-fat accumulation, and beta-oxidation of fatty acid in OLETF rats. Nutrition 17:385-390

Scaglia N, Igal RA (2005) Stearoyl-CoA desaturase is involved in the control of proliferation, anchorage-independent growth, and survival in human transformed cells. J Biol Chem 280: 25339-25349

Staiger K, Staiger H, Weigert C, Haas C, Haring HU, Kellerer M (2006) Saturated, but not unsaturated, fatty acids induce apoptosis of human coronary artery endothelial cells via nuclear factor-kappaB activation. Diabetes 55:3121-3126

Summers SA (2006) Ceramides in insulin resistance and lipotoxicity. Prog Lipid Res 45:42-72

Ussher JR, Koves TR, Cadete VJ, Zhang L, Jaswal JS, Swyrd SJ, Lopaschuk DG, Proctor SD, Keung W, Muoio DM, Lopaschuk GD (2010) Inhibition of de novo ceramide synthesis reverses diet-induced insulin resistance and enhances whole-body oxygen consumption. Diabetes 59:2453-2464

Wei Y, Wang D, Pagliassotti MJ (2007) Saturated fatty acid-mediated endoplasmic reticulum stress and apoptosis are augmented by trans-10, cis-12-conjugated linoleic acid in liver cells. Mol Cell Biochem 303:105-113

Yang G, Badeanlou L, Bielawski J, Roberts AJ, Hannun YA, Samad F (2009) Central role of ceramide biosynthesis in body weight regulation, energy metabolism, and the metabolic syndrome. Am J Physiol Endocrinol Metab 297:E211-E224

Zabala A, Fernandez-Quintela A, Macarulla MT, Simon E, Rodriguez VM, Navarro V, Portillo MP (2006) Effects of conjugated linoleic acid on skeletal muscle triacylglycerol metabolism in hamsters. Nutrition 22:528-533 